\title{
Actualización en Inmunizaciones
}

\section{Generalidades}

Luego del saneamiento ambiental, la implementación de las inmunizaciones (IMN) ha sido la medida de mayor impacto en la salud pública. En su gran mayoría son intervenciones altamente costoefectivas; sin embargo, los niveles de cobertura de la población distan mucho de ser los óptimos.

En primer lugar se harán unas consideraciones generales para el adecuado uso de las IMN y luego se tratarán cada una en particular.

Las vacunas actuales están altamente purificadas de manera que los efectos adversos severos y las reacciones alérgicas son extremadamente raras. Sin embargo deben tomarse precauciones en situaciones especiales:

* Las personas con historia de alergia severa al huevo no deben recibir vacunas hechas en huevos (gripe, sarampión, paperas, fiebre amarilla).

* Las vacunas virales obtenidas en tejidos, generalmente contienen pequeñas dosis de antibióticos (neomicina) a los que pueden ser alérgicos algunos pacientes.

* Las vacunas a virus vivos en general están contraindicadas en pacientes inmunocomprometidos (HIV +, leucemia, linfoma, quimioterapia por cáncer, corticoterapia, etc.) y las mujeres deben evitar el embarazo dentro de los tres meses de aplicada una vacuna de este tipo.

* La administración reciente de inmunoglobulina requiere posponer la aplicación de algunas vacunas a virus vivos y es conveniente esperar 6 semanas luego de su uso para vacunar a un paciente.

* En caso de fiebre marcada se debe posponer la aplicación de una vacuna para no superponer los posibles efectos adversos de la vacunación con los síntomas del paciente y además de asegurar su efectividad.

* Debido a la rara posibilidad de una reacción anafiláctica los pacientes deberían ser observados durante 15 minutos luego de vacunarse.

Desnutrición, fiebre moderada, infecciones de vía aérea superior, diarrea benigna $u$ otras enfermedades menores no son una contraindicación. Si bien la desnutrición extrema (kwashiokor) afecta la inmunidad mediada por células como la de la BCG, no se la considera una contraindicación (aunque puede tener peor tolerancia). La síntesis de anticuerpos respecto a vacunas bacterianas o virales es totalmente normal.

Esquema de vacunación

\begin{tabular}{|c|c|c|}
\hline$\frac{\text { EDAD }}{1 \text { mes }}$ & $\begin{array}{l}\text { OBLIGATORIO } \\
\text { BCG }\end{array}$ & RECOMENDADO \\
\hline$\sum_{\Sigma}^{2 \text { meses } \Sigma}$ & $\begin{array}{l}\text { DPT o Triple (Difteria, Pertusis, Tétanos) } \\
\text { Anti Haemophilus tipo b } \\
\text { Sabín }\end{array}$ & $\begin{array}{l}\text { (sola o como cuádruple } \\
\text { agregada a la DPT) }\end{array}$ \\
\hline$\sum_{\sum}^{4 \text { meses } \Sigma}$ & $\begin{array}{l}\text { DPT } \\
\text { Anti Haemophilus tipo b } \\
\text { Sabin }\end{array}$ & $\begin{array}{l}\text { (sola o como cuádruple } \\
\text { agregada a la DPT) }\end{array}$ \\
\hline $\begin{array}{l}6 \text { meses } \Sigma \\
\Sigma\end{array}$ & $\begin{array}{l}\text { DPT } \\
\text { Anti Haemophilus tipo b } \\
\text { Sabín }\end{array}$ & $\begin{array}{l}\text { (sola o como cuádruple } \\
\text { agregada a la DPI) }\end{array}$ \\
\hline 12 meses & Triple viral: Rubéola + Paperas + Sarampión & \\
\hline 18 meses & $\begin{array}{l}\text { DPT } \\
\text { Anti Haemophilus tipo b } \\
\text { Sabín }\end{array}$ & $\begin{array}{l}\text { (sola o como cuádruple } \\
\text { agregada a la DPT) }\end{array}$ \\
\hline$\sum_{\sum}^{6 \text { años } \Sigma}$ & $\begin{array}{l}\text { BCG } \\
\text { DPT } \\
\text { Sabín } \\
\text { Tripleviral }\end{array}$ & \\
\hline Adolescentes & $\sum$ & $\begin{array}{l}\text { Hepatitis } B *(0,1 y 6 \\
\text { meses })\end{array}$ \\
\hline $\begin{array}{l}16 \text { años y cada } \\
\text { diez años }\end{array}$ & dT (doble adulto) & \\
\hline $\begin{array}{l}\text { 65 años o más } \\
\sum\end{array}$ & $\Sigma$ & $\begin{array}{l}\text { Neumococo } \\
\text { Gripe }\end{array}$ \\
\hline
\end{tabular}

Es obligatoria y gratuita para el personal de salud en relación de dependencia, contratado, becado permanente o transitorio.

(Ley N 24.151 publicada en el B.0. el 27/10/1992)

\section{1) Hepatitis $B(H B)$}

Vacuna: de proteínas recombinantes. Eficacia: mayor del $90 \%$. Posología: tres dosis de $10 \mathrm{mg}$ hasta los 10 años y $20 \mathrm{mg}$ en mayores de 10 años. Primera dosis, la segunda al mes y la tercera a los 6 meses de la primera (o esquema rápido, en caso de exposición o alto riesgo, a los 0,1 y 2 meses y refuerzo al año). Se aplica intramuscular (IM) en muslo hasta los 18 meses y en el deltoides en mayores. Efectos adversos: ligeras reacciones locales (raro): inflamación, picazón.

Dosis de refuerzo: actualmente no se recomienda. Si bien a los 5 - 8 años de completado el esquema se observa una declinación en los títlos de anticuerpos y pasado este tiempo es posible adquirir la infección en forma leve, la vacunación continuaría protegiendo de la hepatitis crónica, (los únicos casos de hepatitis crónica años después de la vacunación, se observaron en pacientes inmunocomprometidos con HIV).

Indicaciones:

* Recién nacidos de madre Hbs Ag positivas (+ gamaglobulina hiperinmune), para lo cual se debe hacer rastreo de Hbs Ag en embarazadas.

*Adolescentes (especialmente antes del inicio de las relaciones sexuales).

\section{Personas de alto riesgo:}

* Personal de salud de psiquiátricos o instituciones para discapacitados mentales, menores o drogadictos.

* Homosexuales, bisexuales, heterosexuales promiscuos o con antecedentes de enfermedades de transmisión sexual (ETS)

* Adictos endovenosos y sus parejas.

* Prisioneros de cárceles.

* Pacientes HIV + .

* Hemodializados o con insuficiencia renal crónica (IRC) prediálisis.

* Receptores frecuentes de hemoderivados.

* Convivientes y contactos sexuales de portadores crónicos o con infección aguda por HB.

* Pacientes con hepatopatías crónicas de otra etiología y deterioro funcional, candidatos a transplante de hígado.

* Viajeros a áreas de alta endemicidad.

En los grupos de alta prevalencia de HB (como adictos u homosexuales) antes de indicar la vacuna puede ser costo-efectivo pedir serología (IgG anticore) y en caso de ser positiva no es necesario vacunar. Esto no es útil en aquellos grupos de baja prevalencia (como los trabajadores de la salud o familiares de portadores) que deben ser vacunados directamente ya que vacunar a alguien que ya tuvo HB no aumenta el riesgo de efectos adversos (sólo que es inútil). No se recomienda vacunar a los compañeros de trabajo o de escuela de portadores crónicos.

La estrategia de vacunar sólo a los grupos de riesgo no disminuyó la incidencia y prevalencia de la enfermedad en la población general. Es por eso que en los Estados Unidos existen recomendaciones de vacunar en forma rutinaria a todos los neonatos (preferentemente antes del alta) y a niños o adolescentes no vacunados (USPSTF). En la Argentina muchos centros de atención y organizaciones médicas como la Sociedad Argentina de Pediatría también recomiendan la vacunación a todos los adolescentes. Esta estrategia parecería ser más efectiva para prevenir la enfermedad que vacunar sólo a los grupos de riesgo. Si bien es costo efectiva, el único problema es quién paga la vacuna ya que es muy cara y aunque está en estudio, aún no está cubierta por el Estado.

Control postvacunal: debe solicitarse anti Hbs luego de 102 meses (y no más) de finalizado el esquema, en pacientes de alto riesgo de HB con probabilidad de respuesta inadecuada (Ej: pacientes hemodializados, huéspedes inmunocomprometidos, incluido HIV; personal de salud; postexposición; niños nacidos de madres $\mathrm{Hbs} \mathrm{Ag+;} \mathrm{adictos} \mathrm{endovenosos;} \mathrm{contac-}$ tos sexuales regulares de portadores de HVB).

Revacunación: si los títulos son no protectores (anti Hbs $<10 \mathrm{mUI} / \mathrm{ml}$ ):

Nueva serie de 3 dosis de $20 \mathrm{mg}$ en el huésped normal y 1 dosis de $40 \mathrm{mg}$ en hemodializados e inmunocomprometidos (fórmula especial de HB Vax II, Engerix B, Bio Vac HB).

\section{Inmunización pasiva ( $\mathrm{Ig} \mathrm{G}$ )}

Si bien la IgG inespecífica en grandes dosis (dos dosis de $0.06 \mathrm{~mL} / \mathrm{Kg}$ IM separadas por 4 semanas) puede ser efectiva, es preferible la IgG especifica para HB (HBIg) cuya efectividad para prevenir la $\mathrm{HB}$ en individuos que tuvieron una exposición directa es mayor del $75 \%$. Si se la aplica junto con la vacuna es aún más efectiva. No está indicada la profilaxis en quienes son IgG anti core positivos o HBsAg positivos.

a) Profilaxis perinatal (madre con hepatitis aguda o portadora crónica de $\mathrm{HBsAg}$ ):

HBIg $0.5 \mathrm{~mL} \mathrm{IM}$ + Vacuna $0.5 \mathrm{ml}$ IM dentro de las 12 hs del nacimiento. Ambas pueden darse al mismo tiempo pero en sitios diferentes. El esquema de vacunación se completará con una segunda dosis de vacuna al 1-2 do mes y tercer dosis al 6-12vo mes. 
b) Profilaxis luego de contacto sexual:

HBIg $0.06 \mathrm{ml} / \mathrm{Kg} \mathrm{IM}+$ Vacuna $1 \mathrm{~mL}$ IM dentro de los 14 días del último contacto sexual. Ambas pueden darse al mismo tiempo pero en sitios diferentes. El esquema de vacunación se completará según lo indicado.

c) Profilaxis luego de exposición percutánea o por mucosas según fuente de contagio y estado del expuesto:

\begin{tabular}{llll}
\hline $\begin{array}{l}\text { Paciente } \\
\text { expuesto }\end{array}$ & \multicolumn{3}{c}{ Fuente de contagio } \\
\hline No vacunado & $\begin{array}{c}\text { HbsAg positivo } \\
\text { HBIg + vacuna }\end{array}$ & $\begin{array}{c}\text { HbsAg negativo } \\
\text { Vacuna }\end{array}$ & $\begin{array}{c}\text { HbsAg desconocido } \\
\text { Vacuna }\end{array}$ \\
\hline Vacunado & $\begin{array}{c}\text { Testear anti HBs } \\
\text { del expuesto }\end{array}$ & Nada & $\begin{array}{l}\text { Testear anti HBs } \\
\text { del expuesto }\end{array}$ \\
& $\begin{array}{l}\text { 1) Inadecuado: HBIg } \\
\text { + Vacuna }\end{array}$ & $\begin{array}{l}\text { 1) Inadecuado: HBIg } \\
\text { + Vacuna }\end{array}$ \\
2) adecuado: Nada & & 2) adecuado: Nada \\
\hline
\end{tabular}

La dosis de HBIg es $0.06 \mathrm{~mL} / \mathrm{Kg}$ IM. Los títulos adecuados de anti-HBs son $\geq 10$ SRU por radioinmunoensayo o positivos por electroinmunoensayo.

2) Hepatitis A (HA)

En nuestro país de endemicidad media-alta la vacunación no está recomendada universalmente.

Tipo: virus inactivo. Posología: Dos dosis de 720 unidades ELISA en menores de 10 años y dos de 1440 en mayores de 10 años a los 0 y 6 meses (excepto VIROHEP-A a 0 y 12 meses). Efectos adversos: dolor en el sitio de inyección y en menos del $10 \%$, malestar y cefalea.

Indicaciones: Personas de alto riesgo contraer o transmitir la HA.

* Personal en contacto con preescolares (jardines maternales, guarderías, etc.), sistemas cloacales y de alimentación

* Pacientes con hepatopatías crónicas y deterioro funcional (pues aumentaría el deterioro)

* Homosexuales varones, HIV +, adictos ev (en los no ev, según el riesgo individual del paciente)

* Considerar en personas institucionalizadas (3er nivel, psiquiátricos, etc.).

En esta población general estaría recomendada la serología previa (en niños de bajo riesgo, que de todas formas se vayan a vacunar, la serología previa se justificaría a partir de los 10 años).

En adultos se estima que sería necesario un refuerzo luego de 10 a 20 años (en evaluación).

Inmunización pasiva: con gammaglobulina inespecífica es efectiva en un 80-90\%. Está indicada en los contactos cercanos de pacientes (miembros de la familia o contactos íntimos; recién nacido de madre ictérica en el momento del parto con diagnóstico de hepatitis A; pacientes que reconocen haber estado expuestos a comida o agua contaminada) pero no en compañeros de escuela o trabajo salvo que se tengan altas sospechas de una transmisión fecal oral. Debe ser administrada lo más tempranamente posible, dentro de los 14 días de la exposición. La dosis usual es de $0.02 \mathrm{ml} / \mathrm{Kg}$

\section{3) Gripe}

Tipo: virus muertos, partes o enteros (polivalente para las cepas esperadas cada año). Eficacia : 70 - 80\% (mayor en jóvenes, menor en viejos). Depende de la coincidencia de las cepas utilizadas con las presentes en la comunidad. Posología: una dosis anual (marzo-abril), IM ó subcutánea (SC) en el deltoides. Efectos adversos: muy rara vez fiebre leve. Contraindicaciones: alergia al huevo y las generales de cualquier vacuna. Enfermedades triviales como las de vía aérea superior no son una contraindicación. Recordar que es importante indicar la vacuna en la época del año adecuada.

Indicaciones: Los grupos con mayor morbi-mortalidad por Gripe.

* Personas $\geq$ a 65 años.

* Pacientes con enfermedades crónicas cardiorespiratorias (niños > 6 meses).

* Pacientes con enfermedades metabólicas (incluida diabetes), hemoglobinopatías, inmunosupresión (incluido HIV) o insuficiencia renal.

* Personal de salud o convivientes en contacto con este grupo de pacientes.

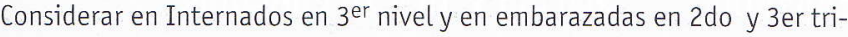
mestre durante época de epidemia.

El uso de amantadina profiláctica en situaciones especiales (epidemias en geriátricos) aumenta el efecto protector en los pacientes que ya habían sido vacunados. Se indica desde la vacunación durante 2 semanas en dosis de $200 \mathrm{mg} /$ día.

La vacuna antigripal, no protege de todos los cuadros virales típicos del invierno. El objetivo de la vacunación es disminuir las complicaciones graves de las infecciones por Gripe (internaciones por cuadros respiratorios, mortalidad, agravamiento de condiciones crónicas -EPOC, insuficiencia cardíaca, etc.). En individuos de bajo riesgo se demostró que la vacunación disminuyó la tasa de ausentismo laboral.

\section{4) Pneumococco}

Tipo: polisacáridos polivalentes purificados. Eficacia: 44 a $81 \%$ contra los 23 serotipos incluídos en la vacuna, que en general son los responsables del 90 \% de las infecciones. Posología: Dosis única IM. Efectos adversos: Muy pocos. Puede dar reacciones locales severas en aquellos pacientes que ya habían sido vacunados (sobre todo si pasaron menos de 5 años). Indicaciones:

* Personas $\geq$ a 65 años

* Pacientes institucionalizados $\geq 50$ años,

* Pacientes $\geq 2$ años con enfermedades crónicas cardiorrespiratorias o diabetes.

* Pacientes que hayan tenido neumonía.

* Asplenia funcional o anatómica (esplenectomía, ausencia congénita del bazo, anemia drepanocítica, e irradiación esplénica)

Revacunación: considerar una segunda y última dosis en la vida a los 10 años (especialmente los de pobre respuesta inmune) y revacunar con vacuna de 23 serotipos a quienes recibieron la antigua de 14 .

Revacunación cada 5 años en grupos de riesgo debido a la pobre respuesta inmunitaria que presentan: cirrosis, alcoholismo (dudoso), IRC, síndrome nefrótico, anemia de células falciformes, mieloma múltiple, enfermedades malignas hematológicas o metastásicas (10 a 14 días previos al tratamiento), HIV-SIDA u otras causas de inmunosupresión como transplantados o corticoterapia (> $20 \mathrm{mg}$ de metilprednisona por más de 2 a 4 semanas).

La vacuna para gripe y la antineumocóccica pueden darse al mismo tiempo en sitios separados.

5) Sarampión-Parotiditis-Rubéola: Triple viral (TV)

Tipo: virus vivos atenuados. Posología: a los 12 meses y al ingreso escolar. Quienes no recibieron estas 2 dosis, deben aplicarse una entre los 13 y 18 años. Contraindicado en embarazadas e inmunocomprometidos y en alergia al huevo. Se aplica por vía SC. Efectos adversos: fiebre $5-15 \%$ y rash $5 \%$ entre $5-12$ días.

Ante contacto con un caso de alguna de estas tres enfermedades la vacunación en los 2-3 días del contagio puede ser una eficaz profilaxis. La vacunación en pacientes inmunizados (por vacunación o por haber tenido la enfermedad) será ineficaz ya que el virus vaccíneo es neutralizado rápidamente pero no hay reacciones en particular. Pasado este tiempo sólo puede utilizarse las gamaglobulinas (ver enfermedades en particular).

\section{6) Rubéola (RB)}

Posología: Quienes no recibieron 2 dosis de Triple Viral, deben aplicarse una entre los 13 y 18 añof. Las mujeres $>18$ años, en edad fértil y sin vacunación completa deben recibir dosis única de antirubeólica. Se aplica por vía SC. Efectos adversos: artralgias (en un $40 \%$ de los adultos dentro de las 3 semanas), fiebre.

Existe una recomendación tipo " $B$ "* de rastrear susceptibilidad a la rubéola (historia de vacunación o serología negativas) a toda mujer en edad fértil en el 1er contacto con el sistema de salud, incluyendo controles pediátricos de sus niños, para reducir el síndrome de rubéola congénita.

El antecedente clínico de haber padecido RB no es suficiente para considerar protegido al paciente debido a la baja especificidad de las manifestaciones clínicas.

Si bien los efectos adversos no son mayores cuando se vacuna a ciegas a quienes ya tuvieron RB, en nuestra población de alta prevalencia de RB es más costo efectivo la serología previa (IgG anti rubeóla).

Deben vacunarse las mujeres susceptibles no embarazadas y embarazadas susceptibles en el postparto inmediato que sean mayores de 18 años (hasta los 18 años corresponde la TV).

El objetivo de la vacunación rutinaria de los niños es prevenir el contagio de las mujeres embarazadas.

Las mujeres vacunadas deben ser advertidas de evitar el embarazo durante los 3 meses posteriores a la vacunación por el riesgo teórico de teratogenia por la vacuna (sin embargo, no se han observado malformaciones en más de 300 mujeres que recibieron la vacuna durante el embarazo o cercano a él, por lo tanto el riesgo teórico es menor al $1 \%$ ).

Inmunización pasiva: en el niño sólo se justifica si son allegados a una embarazada. La administración temprana (hasta 8 días postcontagio) de $20 \mathrm{ml}$ de gamaglobulina inespecífica en embarazadas seronegativas expuestas a la rubéola, o de estado inmunitario ignorado, disminuye significativamente la frecuencia de rubéola congénita. Su administración no altera los test serológicos. 


\section{7) Parotiditis}

Posología: Quienes no recibieron 2 dosis de TV, deben aplicarse una entre los 13 y 18 años. Eficacia de la vacuna monovalente: $90 \%$. Efectos adversos: no significativos (raro: parotiditis).

En mayores de 18 años no estaría justificada su administración, excepto en personal de salud susceptible (aquellos sin antecedentes de enfermedad ni de vacunación previa). En estos casos es preferible dos dosis de TV separadas por un mes (o vacunas monovalentes si hay inmunidad para uno o más de sus componentes).

Inmunización pasiva: con gamaglobulinas inespecíficas $(0.5 \mathrm{~mL} / \mathrm{Kg})$ pasiva se justifica en varones a partir de la pubertad desde el comienzo de la afección, para prevenir complicaciones como la orquitis. La vacunación, para una protección permanente, no puede hacerse hasta 6 semanas más tarde.

\section{8) Sarampión}

Posología: Quienes no recibieron 2 dosis de TV, deben aplicarse una entre los 13 y 18 años. Eficacia de la vacuna monovalente: $90 \%$. Efectos adversos de la vacuna monovalente: fiebre ( 5 - $15 \%$ de 5 a 21 días), rash (5\%). Indicaciones durante brotes epidémicos:

* Todos los niños de 6 a 11 meses de edad deben recibir una dosis de vacuna antisarmpionosa (VAS), dado que el número de niños menores de 1 año representa alrededor del $50 \%$ del total de los casos notificados de sarampión. Esta debe repetirse entre los 12 y 15 meses.

* Todos los niños de 2 a 5 años que no hayan recibido la VAS aunque hayan recibido la dosis de TV correspondiente al año de edad, deben recibir una dosis más de VAS.

* Reforzar el cumplimiento del esquema nacional de vacunación: Todos los niños de 1 año deben recibir vacuna TV y un refuerzo al ingreso escolar.

* Los niños de 7 a 18 años que no hayan recibido 2 dosis de vacuna deben recibir un refuerzo, preferentemente en la forma de vacuna TV.

* Las personas entre 20 y 40 años que estén en mayor riesgo de contacto con casos de sarampión (personal de salud, estudiantes de carreras vinculadas con la salud, docentes, personal de frontera), deben recibir una dosis de VAS, si la serología previa es negativa. Dada la alta prevalencia de seropositividad y la escasez de vacuna actual sería preferible hacer serología especialmente a aquellos nacidos antes de 1970, fecha en que se comenzó la vacunación masiva en la Argentina.

Ante un caso de sarampión se deben realizar acciones de bloqueo: a todas las personas de 6 meses a 40 años de edad en contacto directo con el caso (distancia < a 1 metro). Se les debe aplicar una dosis de VAS antes del tercer día, y entre el tercero y sexto día sólo estaría indicado la inmunización pasiva con Ig G $0.25 \mathrm{ml} / \mathrm{Kg}$ (máximo $15 \mathrm{ml}$ ) en los contactos familiares del paciente que no estén inmunizados. La dosis para los contactos inmunocomprometidos será de $0.5 \mathrm{ml} / \mathrm{Kg}$ (máximo 15 $\mathrm{ml}$ ). Luego de esta fecha no se justificarían intervenciones pues el período de incubación es de 7 días.

\section{9) Polio}

Tipo: virus atenuados (Sabín oral). Posología: 2, 4, 6, 18 meses y 6 años, vía oral. Efectos adversos: parálisis (raro). Contraindicaciones : no debe ser utilizada en adultos ni en niños inmunosuprimidos (en estos casos utilizar vacunas a virus inactivos). No debe aplicarse tampoco a los convivientes de inmunosuprimidos (ya que pueden trasmitirle los virus atenuados). La diarrea no debe considerarse una contraindicación, pero debe administrarse una dosis suplementaria para asegurar una buena cobertura.

\section{0) Haemophilus Influenza tipo B (HIB)}

Tipo: polisacáridos conjugados purificados. Se puede aplicar junto con la DPT como cuádruple e inclusive como quíntuple (agregando poliovirus inactivados, en lugar de la Sabín oral recomendada en la Argentina). Adultos esplenectomizados dosis única. Efectos adversos: reacciones locales leves (en menos del $10 \%$ ).

Posología: cuatro dosis a los 2, 4, 6 y 18 meses IM, pero varía según la edad de inicio del esquema.

\begin{tabular}{ll}
\hline Edad de inicio del esquema & Esquema correspondiente \\
\hline De 2 a 6 meses & $\begin{array}{l}3 \text { dosis con intervalo de } 2 \text { meses y refuerzo } \\
\text { a los } 18 \text { meses }\end{array}$ \\
\hline De 7 a 11 meses & $\begin{array}{l}2 \text { dosis con intervalo de } 2 \text { meses y refuerzo } \\
\text { a los } 18 \text { meses }\end{array}$ \\
\hline De 12 a 14 meses & 1 dosis y refuerzo a los 18 meses \\
\hline De 15 a 59 meses & 1 sola dosis sin refuerzo \\
\hline
\end{tabular}

\section{1) Meningococo}

Está indicada en situaciones de epidemia. En la actualidad se dispone de la vacuna cubana (serotipos B y C) y la americana (serotipos A y C) para mayores de 4 años. Se aplica en dos dosis separadas por 6 a 8 semanas. Vía IM o SC. Su uso rutinario en la situación actual de la Argentina es cuestionable científica y epidemiológicamente.

\section{2) Bordetella Pertussis (BP)}

Tipo: existen 2 vacunas: la de células enteras compuesta por bacilos muertos de BP y la más recientemente desarrollada que es acelular. Posología: 2, 4, 6 , 18 meses y 6 años como triple (DPT) a células enteras, IM. La acelular (DaPT) es una vacuna menos reactógena y sólo se administra después de los 15 meses, por lo que es una alternativa a la cuarta y quinta dosis de DPT. Si bien muchos estudios han demostrado que la seroconversión y eficacia de las vacunas acelulares son superiores a las enteras, es con estas últimas (de un costo muy inferior), con las que se controló el coqueluche en casi todos los países. En ningún caso debe vacunarse para BP a mayores de 7 años por la posibilidad de reacciones adversas y si está contraindicada se completará el esquema infantil con DT. Efectos adversos locales: dolor en el sitio de la inyección, tumefacción, abscesos estériles. Sistémicos: fiebre mayor de $38,3^{\circ} \mathrm{C}$, anorexia, malestar, irritabilidad, vómitos que se observan a las 48 hs. de la aplicación. Reacciones que contraindican futuras dosis: llanto por más de 3 hs. , irritabilidad, fiebre de $40,5^{\circ} \mathrm{C}$ o más, convulsiones, hipotonicidad, encefalopatía, daño neurológico permanente y shock.

\section{3) Difteria}

Tipo: toxoide. Posología: 2, 4, 6, 18 y 6 años como triple (DPT), 16 años como doble adulto (dT) IM. La dT tiene menor concentración de toxoide diftérico (hasta $2.8 \mathrm{UI}$ ) que la doble niños o DT (hasta 30 UI). Si un niño entre 7 y 10 años no estaba vacunado con DPT completará el esquema básico con DT ( 2 dosis separadas por 1-2 meses y refuerzo al año). A partir de los 10 años se utiliza dT pues se asocia con menos efectos adversos. En aquéllos que tienen esquema completo a los 16 años debe indicarse la dT cada 10 años. Es importante utilizar la dT en los refuerzos y no solo la antitetánica pues, aunque la difteria es de baja incidencia en Argentina (2-3 casos notificados por año), está presente en la comunidad y el relajamiento en la vacunación puede conducir a serios brotes epidémicos como ocu rrió en Rusia y Europa del Este en 1994-5. Efectos adversos: similares a los de la antitetánica. Contraindicaciones: reacción anafiláctica a algún componente de la vacuna, enfermedad sistémica grave con o sin fiebre.

Inmunización post exposición: a todos los contactos cercanos se les debe realizar cultivo de fauces independientemente de que estén vacunados o no. Si es positivo se administra penicilina y se completa esquema de vacunación si está incompleto o se administra íntegro, si no se vacunó jamás contra la difteria. Los contactos asintomáticos deben recibir DPT, DT ó dT según corresponda si no la recibieron en los últimos 5 años.

Inmunización pasiva: se realiza con antitoxina equina y la dosis es de 5.000 a 10.000 U IM; si se tiene alta sospecha clínica de difteria debe administrarse sin esperar el resultado de los cultivos, siempre debe consultarse al especialista, debido al riesgo de las reacciones alérgicas al suero de caballo.

\section{4) Têtanos}

Tipo: toxoide. Posología: niños 2, 4, 6, 18 meses y 6 años como triple o DPT. A partir de los 16 años y luego cada 10 años como doble adulto o dT. Quienes no completaron el esquema primario ( 3 dosis en algún momento de la vida) deben hacerlo ( 2 dosis separadas por un mes y una 3 ra al año) y continuar con refuerzos cada 10 años con dT.

Quienes cuentan con el esquema primario no deben reiniciarlo por prolongación del intervalo al refuerzo. Algunos estudios recomiendan que una vez completado el esquema (incluyendo la dosis de los 16 años) no son necesarios refuerzos posteriores hasta los 50 años, aunque si pasaron más de 30 años sin refuerzos sería prudente reiniciarlo, en especial en los ancianos que son el grupo de menor inmunidad y mayor riesgo.

En la Argentina la DPT comenzó a aplicarse a fines de la década del '50, por lo que los nacidos antes de 1960 deberían considerarse carentes de la DPT de la infancia. La OMS recomienda en embarazadas completar un esquema de 5 dosis durante su vida reproductiva y luego continuar con refuerzos cada 10 años. Argentina adhirió a esta recomendación de la OMS. Si nunca fueron inmunizadas el esquema propuesto son 2 dosis separadas por un mes como mínimo y la $2^{\text {da }}$ no más allá de dos semanas antes de la fecha de parto (generalmente al $5^{\text {to }}$ y $7^{\mathrm{mo}}$ mes de embarazo). La $3^{\text {ra }}$ dosis a los 6-12 meses de la última o durante el 6 to mes del embarazo subsiguiente (entre $4^{\text {to }}$ y $8^{\mathrm{vo}}$ ). 
La $3^{\text {ra }}$ dosis a los 6-12 meses de la última o durante el 6to mes del embarazo subsiguiente (entre $4^{\text {to }}$ y $8^{\mathrm{vo}}$ ).

La 4ta a 1-5 años de la última o durante el embarazo subsiguiente La $5^{\text {ta }}$ y última a 1-10 años de la 4ta o durante el embarazo subsiguiente. Efectos adversos: dolor local, ocasionalmente fiebre. Contraindicaciones: las generales de cualquier vacuna.

\section{Inmunización pasiva (Ig G)}

La gamaglobulina ( $\mathrm{IgG}$ ) antitetánica es de plasma de adultos hiperinmunizados con toxoide tetánico. La dosis recomendada es 250 UI IM. En pacientes obesos, con heridas extensas o tratamiento tardío $(>24 \mathrm{Hs}$ ) se utilizan dosis de 500 UI. Por esto, la administración debe hacerse tan pronto como sea posible, según el esquema del siguiente cuadro:

\begin{tabular}{lc|cc|c}
\hline $\begin{array}{l}\text { Historia de vacunación } \\
\text { (Ndosis recibidas) }\end{array}$ & \multicolumn{2}{c}{$\begin{array}{c}\text { Heridas limpias } \\
\text { y menores }\end{array}$} & \multicolumn{2}{c}{ Otras heridas } \\
\hline $\begin{array}{l}\text { Toxoide } \\
\text { SI }^{*}\end{array}$ & $\begin{array}{c}\text { IgG(suero) } \\
\text { No }\end{array}$ & $\begin{array}{c}\text { Toxoide } \\
\text { SI }^{*}\end{array}$ & $\begin{array}{c}\text { IgG(suero) } \\
\text { SI }\end{array}$ \\
\hline $\begin{array}{l}\text { Desconocida 0 }<3 \\
\text { hace más de } 10 \text { años) }\end{array}$ & SI & NO & SI & NO \\
\hline $\begin{array}{l}\text { Certeza de } \geq 3 \text { (última } \\
\text { hace menos de } 10 \text { años) }\end{array}$ & NO & NO & NO-SI\# & NO \\
\hline
\end{tabular}

* Deberían recibir inmunización completa: 2 dosis separadas por 1-2 meses y la tercera a los 6-12 meses.

\#Si la última dosis fue hace más de 5 años deben recibir un refuerzo por ser una herida tetanígena.

\section{5) Varicela}

Tipo: virus vivo atenuado. Posología: Aplicar 1 dosis en < de 13 años (la duración de la inmunidad no ha sido establecida aún y podrían requerirse refuerzos para mantener la protección en la adultez, cuando la varicela es más seria). En personas sanas $\geq 13$ años susceptibles (sin historia de varicela ni de vacunación previa) se dan 2 dosis separadas por 6 a 8 semanas.

Eficacia: 97 \% de seroconversión. En adultos estaría indicada en susceptibles, en trabajadores de la salud, en maestros, empleados de guarderías y se indican dos dosis separadas por 8 semanas.

La vacunación preve 70-90\% de protección contra la infección y un $95 \%$ contra las formas graves. Efectos adversos: dolor y eritema en el sitio de inyección, rash. Contraindicaciones: embarazo, inmunosuprimidos, tuberculosis activa no tratada.

Indicaciones: los esfuerzos de vacunación deberían dirigirse a inmunosuprimidos como leucemia en remisión completa sin quimioterapia ni corticoterapia en las 2 semanas previas y que tengan un recuento de plaquetas $>100.000 / \mathrm{mm} 3$ y linfocitos $>1.200 / \mathrm{mm} 3$, personal de salud y convivientes en contacto con éstos pacientes, personas con alto riesgo de exposición, mujeres en edad fértil no embarazadas ( 3 meses de anticoncepción segura) y podría considerarse en institucionalizados y trabajadores de dichas instituciones. Dada la alta prevalencia de inmunidad entre quienes no tienen historia de varicela sería costo-efectivo realizarles serología si es probable que retornen a la consulta.

\section{6) Tuberculosis: BCG}

Tipo: es una suspensión de bacilos tuberculosos bovinos (Bacilo de Calmette-Guérin). La vacunación está indicada en aquellos países donde la prevalencia de primoinfección es elevada (incidencia anual de $0.5 \%$ ). El objetivo de la vacunación es evitar las formas graves de la enfermedad por lo que está dirigida a los niños, quienes son los más susceptibles de padecerlas. Posología: Dos dosis. La 1 ra dentro del mes de vida y la 2 da al ingreso escolar ( 6 años). La dosis es de $0.1 \mathrm{ml}$ por vía intradérmica en la cara externa del brazo, justo en la inserción del deltoides. La 3ra dosis de BCG que se administraba a los 16 años fue suspendida del esquema oficial (aún indicada cuando carece de dos cicatrices), pero debería ser considerada en el personal de salud, especialmente el de mucho riesgo de exposición a TBC multirresistente. Efectos adversos: inflamación de los ganglios axilares y nódulos supurativos locales. Contraindicaciones absolutas: corticoterapia, inmunosupresión y relativas: neonato $2000 \mathrm{gr}$, prematurez o reacción generalizada de la piel (estos casos deben evaluarse individualmente). Si bien la desnutrición extrema (kwashiokor) afecta la inmunidad celular mediada por células como la de la BCG, aunque puede tener peor tolerancia la OMS no la considera una contraindicación.

\section{Vacunación en el personal de salud}

Antigripal: especialmente para el personal en contacto con pacientes de riesgo. Antihepatitis B: a todo el personal que no tuvo la enfermedad ni fue vacunado. Se realizará estudio serológico post-vacunación en el personal de riesgo de contacto con sangre, secreciones o material punzocortante.

Triple Viral para todo el personal de salud no vacunado (2 dosis separadas por un mes).

Con inmunidad para uno o más de sus componentes puede utilizarse vacuna monovalente

Antisarampionosa: todo personal que no halla recibido ninguna dosis de VAS y con serología negativa deberá recibir 2 dosis preferentemente con TV separadas por un intervalo de mes. Si ya habían recibido una sola dosis se completará el esquema con una 2da.

Antirubeólica: Al personal de ambos sexos susceptible (no vacunados con al menos una dosis). Se puede inmunizar con TV o con vacuna monovalente en caso de requerir sólo inmunización antirubeólica.

Antiparotiditis: el personal susceptible debe ser inmunizado de preferencia con TV sin necesidad de serología previa.

BCG: personal PPD negativo con riesgo de exposición a TBC (especialmente multirresistente).

Vacuna contra la varicela: personal en contacto con inmunosuprimidos.

Como sabemos, las vacunas son el modelo paradigmático de prevención primaria y una vez confirmado su beneficio se deberían aplicar a toda la población. De las 15 enfermedades inmunoprevenibles descriptas, el estado argentino garantiza en forma gratuita (cuando no se agotan las partidas) la provisión de 9: tuberculosis, polio, difteria, tétanos, pertussis, sarampión, rubéola, parotiditis y haemophilus tipo b. Es importante reconocer que por el momento hay ciertas vacunas cuya aplicación masiva no es necesaria o es aún controvertida como la de hepatitis A, varicela y meningococo; y que la industria farmacéutica y los "centros privados de vacunación" presionan para vender más vacunas. Sin embargo, creemos que la no-obligatoriedad de ciertas vacunas, como la de hepatitis B, deja a muchos niños de familias sin recursos, y posiblemente los de mayor riesgo, sin la posibilidad de ser vacunados. Hoy en día las familias deben gastar mucho dinero para vacunar correctamente a sus hijos y las poblaciones susceptibles y mayores deben comprar la vacuna contra la gripe y la neumonía. Creemos que es responsabilidad del Estado determinar qué vacunas debe recibir la población y garantizar un esquema de vacunación universal, obligatorio y gratuito acorde con la realidad.

\section{Dr. Agustín Ciapponi}

Unidad de Medicina Familiar y Preventiva. Hospital Italiano de Buenos Aires.

\section{Bibliografía recomendada}

1. American College of Physicians. American College of Physicians Task Force on Adults Inmunization, Infectious Diseases Society of America. Guide for Adults Inmunization. 3rd ed. Philadelphia. 1994

2. U.S. Preventive Services Task Force. Guide to clinical preventive services. Baltimore: Williams \& Wilkins, 1996.

3. Canadian Task Force on the Periodic Health Examination 1994.

4. Gardner P, et al. Immunization of adults. N Engl J Med 1993;328:1252-8.

5. Gerberding JL. Management of occupational exposure to blood-borne viruses. N Eng J Med 1995;332:444-51.

6. Goroll AH. Primary care medicine. 3rd ed. Philadelphia, PA: J. B. Lippincott, 1996.

7. Nichol KL, et al. The efficacy and cost effectiveness of vaccination against gripe among elderly persons living in the community. $\mathrm{N}$ Engl $\mathrm{J}$ Med 1994;331:778-84.

8. Vega María Elena. Vacunas. Niños, adolescentes y adultos.

9. Kates Christopher J. A handout about tetanus inmunization: influence on inmunization rate in general practice. BMJ 1990; 300:789-790.

10. General recommendations on immunization: recommendations of the advisory Commitee on Immunizaton Practices (ACIP). MMWR Morb Mortal Wkly Rep 1994; 43(RR-1):1-38.

11. Holt Diane M. Recommendations, Usage and efficacy of Immunizatios for the Elderly. Nurse Practitioner 1992; 17(3):51-9.

12. Plotkin \& Mortimer. Vaccines. Second Edition. 